\title{
Behovsutredning og kontakt med hjelpeapparatet hos personer med langvarige psykiske lidelser
}

\author{
Knut W. Sørgaard og Terje Øiesvold \\ Nordland psykiatriske sykehus \\ Korrespondanse: Knut W. Sørgaard, NPS, Kløveråsveien 1, 8002 Bodø \\ Telefon: 75501120 Telefax: 75501234 E-post: ksorgaar@online.no
}

\begin{abstract}
Sørgaard KW, Øiesvold T. Needs and contact with health and social services in persons with long term mental illness. Nor J Epidemiol 2002; 12 (3): 333-338.
\end{abstract}

\section{ENGLISH SUMMARY}

In a rural area in Northern Norway Camberwell Assessment of Needs (CAN), a contact checklist, GAF and BPRS were used to determine the number of met and unmet needs, and extent of contact with 10 different social- and health services in a group of long term psychiatric patients. The group consisted of 33 persons with schizophrenia and 24 persons with anxiety or depressive disorders, both set according to ICD-10. None of the patients were institutionalised at the time of the interview. Only patient-identified needs were used in the analysis. As expected, persons with schizophrenia had a higher number of total needs ( 7.1 and 4.7) and of unmet basic needs (CAN 1-5) and health needs (CAN 6, 7, 9, 10) than persons with anxiety or depression. No difference was found for social needs. In both groups total number of needs (met and unmet) and number of unmet needs was generally found in the areas of activities, psychological distress, psychotic symptoms and social relations. Total number of needs and number of unmet needs correlated positively with symptom-level. A high number of needs (met and unmet) was related to use of primary care or municipality services, whereas a high symptom level was related to use of mental health services. Multiple regression analyses showed that in a model explaining $40 \%$ of the variance, use of services was predicted by low GAF, a high number of patient identified health needs and younger age.

\section{INNLEDNING}

De store reformene innenfor psykisk helsevern de siste tiårene har ført til at pasienter med psykiske lidelser tilbringer det aller meste av tiden utenfor institusjon. Det lokale hjelpeapparatet må derfor kunne levere et bredt spekter av sosiale- og helserelaterte tjenester som inkluderer ordinære helsetjenester, bolig, aktivisering, sosial kontakt og økonomi i tillegg til behandling for psykiske lidelser. Tjenestene må ideelt sett være tilgjengelige, omfattende, koordinerte, akseptable for brukerne og evaluerte (Huxley et al., 1990). Individuelle behovsutredninger er et nødvendig utgangspunkt for organisering av tiltakene (Wing et al., 1992) og er virkemidler som forankrer individuelle behandlingsog oppfølgingsopplegg i samfunnets hjelpesystemer. Det finnes ingen alminnelig akseptert definisjon av behov og heller ingen konsensus om hvilke behovsanalyser som er mest hensiktsmessige, men Camberwell Assessment of Needs (Phelan et al., 1995) har markert seg som det sentrale referansepunktet på området. Tradisjonelt har behovene til psykiatriske pasienter blitt definert av fagfolk, men registreringer i CAN fanger også opp pasientenes egne vurderinger av behov og tiltak. Flere undersøkelser viser et dårlig sammenfall mellom pasienters og fagfolks behovsvurderinger
(Lasalvia et al., 2000; Hansson et al., 2001). Klientfokusert behovsmåling er derfor et nødvendig supplement til servicedefinerte behov.

Et helserelatert behov kan sies å være til stede når en person har vanskeligheter innenfor fysisk, psykisk og sosial fungering som det i prinsippet finnes en eller annen form for hjelp for. Det er imidlertid ingen nødvendig sammenheng mellom opplevde behov, ønsker om hjelp og faktisk bruk av helsetjenester. Man kan for eksempel ha behov for behandling uten å ønske det, man kan ønske behandling uten at et behov er til stede, og man kan ha behov og ønsker uten å få behandling. Vi vet etter hvert en god del om generelle behovsprofiler hos personer med schizofreni, og det er godt kjent at personer med denne lidelsen generelt er avhengig av et vidt spekter av offentlige tjenester (Attkisson et al., 1992; Sørgaard et al., 2002). Mindre er imidlertid kjent om hvilke behov som er til stede hos personer med andre typer vedvarende lidelser. Det er også uklart på hvilken måte behovsanalyser kan utvide forståelsen av hjelpsøkingsprosesser.

Denne undersøkelsen tar for seg behovsanalyser i to grupper pasienter med langvarig psykisk problematikk, henholdsvis personer med schizofrenidiagnose og personer med langvarig angst- og/eller depresjonsproblematikk. Hensikten er å sammenligne omfanget 
av dekkede og udekkede behov i de to gruppene, deres kontakt med ulike deler av hjelpeapparatet samt forsøke å finne faktorer som predikerer bruk av tjenester.

\section{UTVALG OG METODE}

\section{Utvalg}

Undersøkelsen er en tverrsnittsstudie basert på to utvalgte grupper av pasienter (tabell 1). Inklusjonskriteriene var slik: (a) enten schizofrenidiagnose $i$ henhold til ICD-10 eller angst- eller depresjonsdiagnose også i henhold til ICD-10. (b) De skulle ha hatt diagnosen $i$ minst ett år forut for inklusjonstidspunktet i studien, (c) alder mellom 25 og 55 år på inklusjonstidspunktet, (d) minimum en poliklinisk kontakt i 12-månedersperioden forut for inklusjon. Kriteriet ble valgt fordi det var nødvendig å identifisere deltagere vha. lokale pasientregistre. Daghospital og psykiatriske dagenheter ble betraktet som polikliniske tiltak. (e) De skulle ikke være institusjonalisert. Institusjonalisering ble definert som bosituasjoner med 24 timers bemanning. Pasienter som tilfredsstilte kriteriene ble funnet $\mathrm{i}$ pasientregistrene og ble kontaktet skriftlig. I angstdepresjonsgruppa deltok $56 \%$ av de som fikk forespørsel om å delta, mens andelen var $76 \%$ hos personer med schizofreni. Til sammen ble 23 personer med angst eller depresjon og 33 personer med schizofreni intervjuet. Undersøkelsen er godkjent av Etisk komité for medisinsk forskning i helseregion V og Datatilsynet.

Tabell 1. Karakteristika ved de deltagende personene.

\begin{tabular}{lcc}
\hline & \multicolumn{2}{c}{$(\mathrm{n}=56)$} \\
\cline { 2 - 3 } Karakteristika & $\begin{array}{c}\text { Schizofreni (SD) } \\
(\mathrm{N}=33)\end{array}$ & $\begin{array}{c}\text { Angst/depresjon (SD) } \\
(\mathrm{N}=23)\end{array}$ \\
\hline Alder & $35,1(8,4)$ & $41,6(12,6)$ \\
Kjønn & & \\
Menn & $48 \%$ & $39 \%$ \\
Kvinner & $52 \%$ & $61 \%$ \\
Bosituasjon & & \\
Eget hus/leilighet & $73 \%$ & $96 \%$ \\
Skjermet/tilrettelagt & $27 \%$ & $4 \%$ \\
Ekteskapelig status & & \\
Gift & $12 \%$ & $22 \%$ \\
Enslig & $82 \%$ & $35 \%$ \\
Enke/skilt/annet & $6 \%$ & $43 \%$ \\
Antall barn (gjsn.) & 0,2 & 1,4 \\
Arbeid & $6 \%$ & $15 \%$ \\
GAF* & $42(11,3)$ & $62(11,0)$ \\
BPRS* & $37,1(8,0)$ & $24,2(4,0)$ \\
\hline
\end{tabular}

*) Forskjell mellom gruppene $\mathrm{p}<0,001$

\section{Instrumenter}

Data er registrert ved hjelp av disse instrumentene: Camberwell Assessment of Needs ver. 3.0 (CAN), en sjekkliste for kartlegging av kontakt og tilfredshet med forskjellige deler av hjelpeapparatet, BPRS-K (Brief
Psychiatric Rating Scale; Overall \& Gorham, 1962) og GAF (American Psychiatric Association, 1994) for måling av symptomer og funksjonsnivå. CAN er utviklet for å identifisere alvorlige udekkede behov hos personer med alvorlige sinnslidelser som bor utenfor institusjon (Phelan et al., 1995). Den omfatter 22 behovsområder (se tabell 2), og er todelt med separate intervjuer av pasient og en fagperson som foreslås av brukeren. For hvert av de 22 behovsområdene er det fire underseksjoner (alvorlighet: intet problem, moderat problem og alvorlig problem, omfang av hjelp fra venner og slektninger og hjelpeapparatet, hvor adekvat hjelpen er og tilfredshet med hjelpen). Til analysene er det gjort bruk av tre samleskårer: (i) Grunnleggende behov (1, 2, 3, 4 og 5 i tabell 2), (ii) helsebehov (6, 7, 9 og 10) og (iii) sosiale behov (14, 15 og 16). I denne artikkelen benyttes bare pasientskårede behov. Sosial integrering ble målt ved hjelp av Interview Schedule for Social Interaction (ISSI) (Henderson et al., 1980). Skjemaet har 30 ledd og er basert på ideen om at sosiale relasjoner reflekterer to forhold: kontakt med andre og hvilke muligheter til dypere følelsesmessige relasjoner denne kontakten innebærer. I denne artikkelen kalles de henholdsvis for sosial kontakt og emosjonell integrering. Skjemaet fanger også opp personenes tilfredshet med sin sosiale kontakt og sosiale integrering. Sjekklisten (Sørgaard et al., 2002) for kontakt med hjelpeinstanser omfatter følgende kategorier (1) lavnivåkontakter innenfor og (2) utenfor psykisk helsevern (medikamentutdeling, uregelmessige avtaler med personer i helse- og sosialtjenesten eller psykisk helsevern), (3) støttefunksjoner innenfor psykisk helsevern (regelmessig kontakt med miljøpersonell), (4) støttefunksjoner utenfor psykisk helsevern (regelmessig kontakt med sosialkontor, hjemmetjeneste, hjemmesykepleier etc.) - begge med formål å avhjelpe problemer og bedre pasientens livskvalitet. (5) Leger innenfor og (6) leger utenfor psykisk helsevern hvor kontakten i begge tilfeller ble forutsatt å være regelmessig og rettet inn mot ønsker om å redusere symptomer eller gjenopprette mental helse. (7) Psykoterapi (minst to avtaler per måned med målsetting å redusere symptomer eller gjenopprette mental helse), (8) dagtilbud (deltagelse sosiale grupper, møtevirksomhet, dagsenter), opphold på (9) somatisk eller (10) psykiatrisk sykehus i løpet av de siste seks måneder. Til enkelte av analysene ble det konstruert en sum-skår total kontakt som er summen av personens kontakter med samtlige av disse etatene.

\section{Analyser}

Variabler som avvek betydelig fra normalfordeling ble rekodet for å oppnå en tilnærmet normalfordeling og parametrisk statistikk ble benyttet. Det ble gjort følgende analyser: korrelasjoner, T-tester, chi-kvadrat og multippel regresjon. Ikke-parametriske metoder (Mann-Whitney) ble benyttet ved noen gruppesammenligninger. Dataanalyser ble utført med SPSSWIN 10.0 . 


\section{RESULTATER}

\section{Dekkede og udekkede behov}

Tabell 2 viser hvor stor andel av det samlede utvalget som oppgir at de aktuelle behovsområdene oppleves som dekket eller udekket. I CAN er en bekreftelse på at et behov er til stede nødvendig for en videre vurdering av om behovet (a) er tilstrekkelig avhjulpet (dekket behov), eller (b) utilstrekkelig avhjulpet ved at hjelpetiltak enten ikke er utløst eller er utilstrekkelige (udekket behov).

Tabell 2 viser at de mest sentrale behovsområdene (dekkede $o g$ udekkede behov) er aktivisering, psykologiske belastninger, psykotiske symptomer og sosiale relasjoner. De viktigste områdene for udekkede behov er psykologiske belastninger, sosiale relasjoner, intime relasjoner og informasjon om tilstand og behandling.

I vurderingen av hvorvidt man mener å motta riktig hjelp, kommer disse områdene dårligst ut: trygdeytelser, informasjon og tilstand og behandling, alkoholproblemer og omsorg for barn. Forskjellen i totalt antall registrerte behov (dekkede og udekkede) mellom personer med schizofreni og de med angst eller depresjon var signifikant ( $p<0,05$; hhv. 7,1 og 4,7). De første rapporterte flere grunnleggende- $(p<0,001)$ og helsebehov ( $p<0,05)$ enn angst eller depresjons-gruppa, mens det ikke var signifikante forskjeller i sosiale behov. Det var ikke forskjeller i udekkede behov mellom gruppene. Gjennomsnittlig antall udekkede behov totalt var 2,8 (schizofreni) og 2,2 (angst/depresjon). Det var ikke signifikante forskjeller mellom menn og kvinner på noen av behovsgrupperingene, og heller ingen alderskorrelasjoner.

\section{Symptomer, funksjonsnivå og behovsgrupper}

GAF korrelerte $-0,37(\mathrm{p}<0,01)$ med antall helsebehov, GAF og BPRS hhv. $-0,58$ og 0,52 med basale behov (begge $\mathrm{p}<0,001$ ) og $-0,31$ og 0,28 (begge $\mathrm{p}<$ $0,05)$ med sosiale behov. Summen av dekkede og udekkede behov korrelerte $-0,57(\mathrm{p}<0,01)$ med GAF og 0,46 $(0,01)$ med BPRS. Antall udekkede behov korrelerte $-0,43$ med GAF $(\mathrm{p}<0,01)$ og 0,33 ( $\mathrm{p}<$ $0,05)$ med BPRS.

\section{Sosiale relasjoner}

Personer med schizofreni skåret signifikant lavere $(\mathrm{p}<0,01)$ på samtlige fire ISSI-dimensjoner (sosial kontakt/tilfredshet med sosial kontakt og emosjonell integrering/tilfredshet med emosjonell integrering) enn gruppa med angst eller depresjon.

\section{Kontakt med hjelpeapparatet}

Tabell 3 gir en oversikt over hvorledes kontakten med ulike etater fordelte seg mellom de to gruppene. Fire av fem hadde benyttet lavnivåkontakter utenfor psykisk helsevern, mens om lag en av tre hadde kontakt med følgende etater: lavnivåkontakter innenfor psykisk helsevern, psykoterapi og psykiatrisk sykehus, støttefunksjoner utenfor psykisk helsevern og allmennpraktiserende leger. Personer med schizofreni hadde mye mer omfattende kontakt med hjelpeapparatet enn de med angst eller depresjon (hhv. 3,2 $\pm 1,4$ vs. 1,7 \pm $1,6, \mathrm{p}<0,001)$. De gjorde signifikante større bruk av lavnivåkontakter innenfor psykisk helsevern, støttefunksjoner utenfor psykisk helsevern, støttefunksjoner innenfor psykisk helsevern, dagbehandling og psykia-

Tabell 2. Andel med moderate/dekkede og alvorlige behov (andel personer uten behov er ikke vist), mottatt riktig hjelp (ja/nei) og tilfredshet med hjelpen (ja/nei). Prosentvise angivelser $(\mathrm{N}=56)$.

\begin{tabular}{|c|c|c|c|c|}
\hline Behovsområde & $\begin{array}{c}\text { Moderat eller } \\
\text { avhjulpet behov }\end{array}$ & $\begin{array}{c}\text { Alvorlig } \\
\text { udekket behov }\end{array}$ & Riktig hjelp & $\begin{array}{l}\text { Tilfredshet } \\
\text { med hjelp }\end{array}$ \\
\hline 1. Bosituasjon & 20 & 4 & 77 & 77 \\
\hline 2. Mat & 18 & 5 & 92 & 92 \\
\hline 3. Ta vare på hjemmet & 27 & 4 & 71 & 71 \\
\hline 4. Hygiene & 11 & - & 100 & 100 \\
\hline 5. Aktivisering & 44 & 14 & & 42 \\
\hline 6. Fysisk helse & 23 & 12 & 50 & 45 \\
\hline 7. Psykotiske symptomer & 34 & 21 & 81 & 68 \\
\hline 8. Informasjon om tilstand og behandling & 27 & 27 & 10 & 7 \\
\hline 9. Psykologisk belastning & 37 & 36 & 32 & 27 \\
\hline 10. Egen sikkerhet & 12 & 9 & 42 & 33 \\
\hline 11. Andres sikkerhet & 5 & - & 33 & 33 \\
\hline 12. Alkohol & 5 & 5 & 17 & 17 \\
\hline 13. Narkotika & 2 & 2 & 100 & 100 \\
\hline 14. Sosiale relasjoner & 29 & 35 & 38 & 49 \\
\hline 15. Intime relasjoner & 14 & 30 & 23 & 25 \\
\hline 16. Seksuelle problemer & 14 & 7 & 25 & 25 \\
\hline 17. Omsorg for barn & 4 & 5 & 20 & 20 \\
\hline 18. Grunnleggende skolegang & 0 & 2 & 100 & 100 \\
\hline 19. Telefon & 4 & 2 & 33 & 33 \\
\hline 20. Transport & 4 & 9 & 29 & 29 \\
\hline 21. Penger & 20 & 9 & 75 & 56 \\
\hline 22. Trygdeytelser & 9 & 18 & 7 & 7 \\
\hline
\end{tabular}


Tabell 3. Andel som hadde kontakt med aktuelle instanser (prosent). Forskjeller schizofreni- og angst-depresjonsgruppa (chi-kvadrat).

\begin{tabular}{lccc}
\hline & Schizofreni & Angst-depresjon & Forskjeller S/AD \\
\hline Lavnivå-kontakt utenfor psykisk helsevern & 81 & 74 & i.s. \\
Lavnivå kontakt innenfor psykisk helsevern & 42 & 17 & $3,69^{*}$ \\
Støttefunksjoner utenfor psykisk helsevern & 58 & 4 & $16,71^{* * *}$ \\
Støttefunksjoner innenfor psykisk helsevern & 19 & 0 & $5,01^{*}$ \\
Allmennpraktiserende leger & 35 & 30 & i.s. \\
Leger innenfor psykisk helsevern & 13 & 4 & i.s. \\
Psykoterapi & 39 & 35 & i.s. \\
Dagbehandling & 42 & 0 & $12,70^{* * *}$ \\
Somatisk sykehus & 16 & 4 & i.s. \\
Psykiatrisk sykehus & 45 & 13 & $6,31^{* *}$ \\
\hline
\end{tabular}

$* \mathrm{p}<0,05 ; * * \mathrm{p}<0,01 ; * * \mathrm{p}<0,001$

trisk sykehus. Leger ansatt i psykisk helsevern ble minst benyttet. Det var ingen forskjeller mellom menn og kvinner i total kontakt, mens alder korrelerte $-0,41$ $(\mathrm{p}<0,01)$ med total kontakt.

\section{Bruk av tjenester, symptomer/funksjonsniva og dekkede/dekkede behov}

Total kontakt korrelerte $-0,44(\mathrm{p}<0,001)$ med GAF og 0,39 med BPRS $(p<0,01)$. Lavere GAF og høyere BPRS $(p<0,01)$ ble funnet hos brukere av støttefunksjoner utenfor psykisk helsevern, brukere av dagsenter $(\mathrm{p}<0,05)$ og psykiatrisk sykehus $(\mathrm{p}<0,01)$. Total kontakt korrelerte $0,43(p=0,01)$ med antall dekkede og udekkede behov, $0,45(\mathrm{p}<0,001)$ med helsebehov, $0,43(p=0,01)$ med basale behov og 0,31 ( $p<0,05)$ med antall udekkede behov. Flere dekkede og udekkede behov ble rapportert av personer som hadde kontakt med allmennpraktikere $(\mathrm{p}<0,05)$, lavnivåkontakter ( $\mathrm{p}$ $<0,001)$ og støttefunksjoner $(p<0,05)$ utenfor psykisk helsevern.

\section{Variabler som predikerer kontakt}

Variabler som i univariate analyser viste relasjoner til variabelen total kontakt med p-verdi mindre enn 0,25 (Hosmer \& Lemershow, 1989) ble brukt som uavhengige variabler $\mathrm{i}$ en multippel regresjonsanalyse hvor total kontakt var avhengig variabel. Aktuelle variabler var GAF, BPRS, alder, kjønn, bosituasjon, grunnleggende behov, helsebehov, sosiale behov, sosiale kontakter og tilfredshet med emosjonell integrering. Resultatene av regresjonsanalysen er vist i tabell 4 . Tabellen viser at kontakt med hjelpeapparatet er assosiert med lavere alder, mange symptomer og lavt funksjonsnivå og mange selvopplevde helsebehov.

Tabell 4. Faktorer assosiert med total kontakt. Lineær regresjon, simultan.

\begin{tabular}{lccc}
\hline Variabel & Beta & $95 \%$ CI & Adj. $\mathrm{R}^{2}$ \\
\hline Alder & $-0,04$ & $-0,08,-0,01$ & 0,16 \\
GAF & $-0,04$ & $-0,07,-0,01$ & 0,14 \\
Helsebehov & 0,50 & $0,11,0,89$ & 0,20 \\
\hline Total modell adj. $\mathrm{R}^{2}$ & & & 0,40 \\
\hline
\end{tabular}

\section{DISKUSJON}

Undersøkelsen viser som forventet forskjeller i antall dekkede og udekkede behov blant personer med schizofreni sammenlignet med personer med angst eller depresjoner. Personer med schizofrenidiagnose oppgav flere helsebehov (somatisk helse, psykotiske symptomer, psykologisk belastning, suicidalitet) og flere grunnleggende behov (bosituasjon, mat, egenomsorg, aktivisering, ta vare på hjemmet) mens det ikke var noen forskjell i sosiale behov. Jo flere basale behov og helsebehov jo høyere symptomnivå, men denne sammenhengen fantes ikke for de sosiale behovenes vedkommende. Sosial funksjonssvikt beskrives som et nøkkelkjennetegn ved schizofreni (Mueser \& Bellack, 1998), og skåringene på ISSI viste systematiske forskjeller på alle fire skalaene i schizofrenigruppas disfavør (omfang av sosial kontakt/tilfredshet med disse kontaktene og omfang av følelsesmessig integrering/tilfredshet med den følelsesmessige integreringen), med dette kom altså ikke til uttrykk som subjektivt rapporterte behov for hjelp.

Gjennomsnittlig antall behov (dekkede og udekkede) var 7,1 i schizofrenigruppa og 4,7 hos personer med angst eller depresjon, i utvalget under ett 6,1. For personer med schizofreni var dette noe høyere enn i en nylig gjennomført nordisk multisenterundesøkelse (Hansson et al., 2001), men lavere enn i Phelan og medarbeideres (1995) undersøkelse fra England. I to svensk undersøkelser, hvor halvparten hadde psykosediagose (Hansson et al., 1995; Arvidson, 2001) var gjennomsnittlig behovsantall hhv. 5,9 og 6,1. Summen av dekkede og udekkede behov korrelerte moderat med symptombelastning og funksjonsnivå og med omfanget av kontakt med hjelpeapparatet: jo flere symptomer og behov, jo mer kontakt med hjelpeapparatet.

Viktigere enn antall behov er antagelig hvilke behovsområder som nevnes hyppigst. Psykologiske belastninger, sosiale relasjoner, aktivisering, psykotiske symptomer og informasjon om tilstand og behandling ble oftest oppgitt. Flest udekkede behov ble funnet på stort sett de samme områdene. Både psykologiske belastninger og psykotiske symptomer er områder som 
krever behandlingstiltak, og de høye angivelsene av udekkede behov kan sees på som uttrykk for behandlingsopplegg som ikke er optimale. Behandlingstiltakene for personer med schizofreni beskrives ofte nokså negativt, og Fenton \& Schooler (2000) karakteriserer for eksempel det meste av dem (riktignok ut fra amerikanske erfaringer) som 'crude, clumsy fumbling'. Psykisk helsevern er også ofte sent ute med å ta veldokumenterte behandlingsmetoder i bruk. De nevnte behovsområdene er stort sett sammenfallende med undersøkelser fra Sverige (Hansson et al., 1995; Ericson et al., 1997).

Det var en tendens til at personer med mange behov hadde mer kontakt med tjenester utenfor psykisk helsevern (allmennpraktikere, støttefunksjoner og lavnivåkontakter), mens de med høy symptombelastning oftere var brukere av helsetjenester (psykiatrisk sykehus, dagtilbud). Dette kan sees som en hensiktsmessig bruk av tjenestene: behandlingskrevende pasienter graviterte mot helsetjenestene, mens pasienter med mange og forskjelligartede behov får mer kommunal oppfølging. Personer med schizofrenidiagnose hadde $\mathrm{i}$ gjennomsnitt kontakt med nesten dobbelt så mange instanser som de med angst og depresjon og undersøkelsen bekrefter ikke overraskende den store avhegigheten mange med denne diagnosen står i overfor hjelpeapparatet. De mest benyttede tjenestene totalt sett var lavnivåkontakter innenfor psykisk helsevern, psykoterapi og psykiatrisk sykehus, støttefunksjoner utenfor psykisk helsevern, og allmennpraktiserende leger. Leger ansatt i psykisk helsevern ble minst benyttet, men noe av denne kontakten er fanget opp i psykoterapi-kategorien. I en større nordisk schizofreniundesøkelse (Sørgaard et al., 2002) fant vi at kontakt med allmennpraktikere syntes å være del av et ruralt hjelpsøkingsmønster, mens oppfølging fra leger ansatt i psykisk helsevern karakteriserte behandlingen i større byer. Tilfredsheten med tjenestene var lavest på områdene informasjon om tilstand og behandling, omsorg for barn, intime relasjoner og seksuelle problemer. Misnøye med den informasjonen man får går igjen i brukerundersøkelser utført innenfor psykisk helsevern (Sørgaard, 1996; Gjerden, 1997). Regresjonsanalysene av hvilke faktorer som er assosiert med en mer omfattende kontakt med hjelpeapparatet viste ikke overraskende at psykiske problemer (lav GAF) og høy skåre på helsebehov sammen med lav alder predikerte mange kontakter. Betydningen av høy symptombelastning gir seg selv. Høy skår på helsebehov kan sees på som et pasientmål på ubehag og plager og fanger delvis opp noe av det samme som intervjuervurdert symptombelastning. Når lav alder er assosiert med høyere forbruk av tjenester kan det være et uttrykk for at hjelpeapparatet mobiliserer sterkere rundt personer når de psykiske vanskene er av relativt ny dato.

Svakheter ved undersøkelsen. (1) Antall intervjuede er ikke spesielt høyt, generaliserbarheten av resultatene er usikker. Dette desto mer ved at kontakt- og forbruksmønster nødvendigvis gjenspeiler lokale forhold som utbygging og tilgjengelighet. (2) Deltagerprosenten spesielt i angst/depresjons-gruppa var lav. (3) Kravet om minimum en poliklinisk kontakt i løpet av de siste 12 månedene kan, selv om begrunnelsen for kriteriet var av rent utvalgsteknisk art (tilgang til lokale pasientregistre) for angst/depresjonsgruppas vedkommende ha ført til at mindre belastede personer kom inn i undersøkelsen. Imidlertid er gjennomsnittstallene på dekkede og udekkede behov temmelig like svenske undersøkelser med lignende pasientsammensetning, men med andre seleksjonsprosedyrer.

\section{REFERANSER}

American Psychiatric Association (1994). Diagnostic and statistical manual of mental disorders $4^{\text {th }}$ edn. (DSM $I V)$. APA, Washington DC.

Arvidson H (2001). Needs assessed by patients and staff in a Swedish sample of severely mentally ill subjects. Nord J Psychiatry, 55, 311-317.

Attkisson C, Cook J, Karno M, Lehman A, McGlashan TH, Meltzer HY, O’Connor M, Richardson D, Rosenblatt A, Wells K, Williams J, Hohman AA (1993). Clinical Service Research. Schizophr Bull, 18, 561-626.

Ericson BG, Hansson J-H, Teike T (1997). Urgent need for a Need Assessment Scale in monitoring social support. A validation study on the Swedish version of the Camberwell Assessment of Need. Nord J Psychiatry, 51, 173-182.

Fenton WS, Schooler NR (2000). Editors' introduction: evidence-bases psychosocial treatment for schizophrenia. Schizophr Bull, 26, 1-3.

Gjerden P (1997). A survey of patient satisfaction as a means of evaluating qualty of care in an open psychiatric ward. Nord J Psychiatry, 51, 235-242.

Hansson L, Björkman T, Svensson B (1995). The assessment of needs in psychiatric patients. Acta Psychiatr Scand, 92, 285-293.

Hansson L, Vinding HR, Mackeprang T, Sourander A, Werdelin G, Bengtsson-Tops A, Bjarnason O, Dybbro J, Nilsson L, Sandlund M, Sørgaard K, Middelboe T (2001). Comparison of key worker and patient assessment of needs in schizophrenic patients living in the community: a Nordic multicentre study. Acta Psychiatr Scand, 103, 45-51. 
Henderson S, Duncan-Jones P, Byrne DG, Scott R (1980). Measuring social relationships. The Interview Schedule for Social Interaction. Psychol Med, 10, 723-734.

Hosmer DW, Lemeshow S (1989). Applied logistic regression. Interpreting and using regression. New York: John Wiley \& Sons.

Huxley P, Hagan T, Hennelly R, Junt J (1990). Effective community mental health sercices. Aldershot: Avebury.

Kent S, Fogarty M, Yellowlees P (1995). A review of studies of heavy users of psychiatric services. Psychiatric Services, 46, 1247-1253.

Lasalvia A, Ruggeri M, Mazzi MA, Dall'Agnola RB (2000) The perception of needs for care in staff and patients in community-based mental health services. The South-Verona outcome procjet. Acta Psychiatr Scand, 102, 366-375.

Mueser KT, Bellack AS (1998). Social skills and social functioning. I: Mueser KT, Tarrier N, red. Handbook of social functioning in schizophrenia. Boston: Allyn and Bacon, 79-95.

Overall JE, Gorham DR (1962). Brief Psychiatric Rating Scale. Psychol Rep, 10, 799-812.

Phelan M, Slade M, Thornicroft G, Dunn G, Halloway F, Wykes T, Strathdee G, Loftus L, McCrone P, Hayward P (1995). The Camberwell Assessment of Need: The validity and reliability of an instrument of assess the needs of people with severe illness. Br J Psychiatry, 167, 589-595.

Sørgaard KW (1998). Gjennom pasientenes øyne. Behandlingstilbudet ved et psykiatrisk sykehus vurdert av pasientene. Tidsskr Nor Psykologforen, 35, 433-443.

Sørgaard KW, Sandlund M, Heikkilä J, Hansson LM, Bengtsson-Tops A, Bjarnason O, Karlsson H, Mackeprang T, Merinder L, Nilsson L, Vinding H, Middelboe T (2002). Schizophrenia and contact with health and social services. A Nordic multi-centre study. Nord J Psychiatry, accepted for publication.

Wing JK, Brewin CR, Thornicroft G (1992). Defining mental health needs. I: Thornicroft G, Brewin CR, Wing J, red. Measuring mental health needs. London: Gaskill, 217-226. 